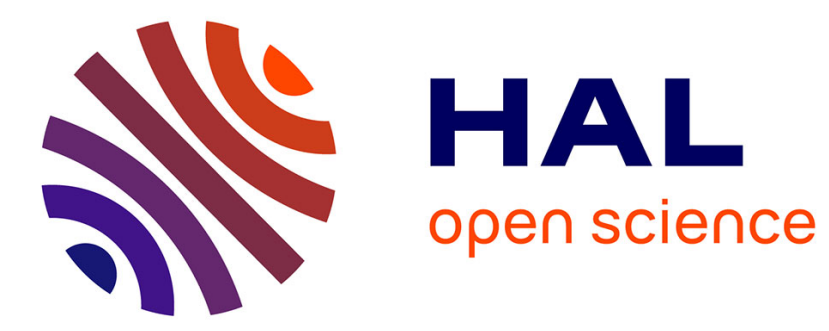

\title{
Self Field Effect Compensation in an HTS Tube
}

Bruno Douine, Kévin Berger, Jean Lévêque, Denis Netter, Olivia Arbey, Nancy Barthelet

\section{To cite this version:}

Bruno Douine, Kévin Berger, Jean Lévêque, Denis Netter, Olivia Arbey, et al.. Self Field Effect Compensation in an HTS Tube. IEEE Transactions on Applied Superconductivity, 2008, 18 (3), pp. 1698-1703. 10.1109/TASC.2008.2000903 . hal-00348415

\section{HAL Id: hal-00348415 https://hal.science/hal-00348415}

Submitted on 18 Dec 2008

HAL is a multi-disciplinary open access archive for the deposit and dissemination of scientific research documents, whether they are published or not. The documents may come from teaching and research institutions in France or abroad, or from public or private research centers.
L'archive ouverte pluridisciplinaire HAL, est destinée au dépôt et à la diffusion de documents scientifiques de niveau recherche, publiés ou non, émanant des établissements d'enseignement et de recherche français ou étrangers, des laboratoires publics ou privés. 


\title{
Self Field Effect Compensation in an HTS Tube
}

\author{
Bruno Douine, Kévin Berger, Jean Lévêque, Denis Netter, Olivia Arbey, and Nancy Barthelet
}

\begin{abstract}
It is well known that the critical current density $J_{c}$ of a superconducting material depends on the magnetic flux density $B$. There exists an electric method to measure the $J_{c}(B)$ deduced from the $U(I)$ measurements. The problem with this method is the self field effect because the magnetic flux density is always the sum of the applied magnetic flux density and the self magnetic flux density. This paper presents a special experimental arrangement, compensating fully or partially the self magnetic flux density in an HTS tube. It allows characterizing the true zero magnetic flux density behaviour of the superconducting material. The experimental results of the compensation are discussed. A theoretical analysis based on Bean's model is presented and gives results close to the experimental ones. The proposed compensation is not perfect but the experiments and the theoretical analysis allow validation of the compensation principle.
\end{abstract}

Index Terms-Critical current density, self field effect, superconductor.

\section{INTRODUCTION}

$\mathbf{I}$ T IS well known that the critical current density $J_{c}$ in a superconducting material depends on the magnetic flux density $B$. The $J_{c}(B)$ characteristic is very important to calculate $\mathrm{AC}$ losses in superconducting wires. Indeed, the evaluation of these losses is necessary for the design of the cooling system for any superconducting device. The superconducting power cable geometry is similar to that of a tube [1], [2]. Despite the inhomogeneous nature of power cables, the loss is often compared to the monoblock model using average current densities and magnetic flux density. For this reason it is important to know well the $J_{c}(B)$ dependence of a tube.

Measurements of $J_{c}(B)$ can be achieved by electrical transport (direct) [3] or magnetic (indirect) [4] methods. In this paper, the electrical method used to define the $J_{c}(B)$ of a superconducting tube is studied. Electrical transport measurements are achieved by the standard four-probe technique, which involves injecting a dc current $I$ in the superconducting tube and measuring the voltage drop $U$ [3]. Throughout this paper, the extremity effects are neglected because the voltage taps are sufficiently distant from the tube extremities. The critical current

Manuscript received October 5, 2007; revised January 14, 2008, March 5, 2008, and March 8, 2008. First published June 27, 2008; current version published September 4, 2008. This paper was recommended by Associate Editor J. Willis.

B. Douine, J. Lévêque, D. Netter, O. Arbey, and N. Barthelet are with the University of Nancy, Groupe de Recherche en Electrotechnique et Electronique de Nancy, 54506 Vandoeuvre, France (e-mail: bruno.douine@ green.uhp-nancy.fr; jean.leveque@green.uhp-nancy.fr; denis.netter@green.uhp-nancy.fr).

K. Berger is with the Grenoble Electrical Engineering Laboratory, 38042 Grenoble, France (e-mail: Kevin.Berger@g2elab.inpg.fr).

Color versions of one or more of the figures in this paper are available at http://ieeexplore.ieee.org.

Digital Object Identifier 10.1109/TASC.2008.2000903

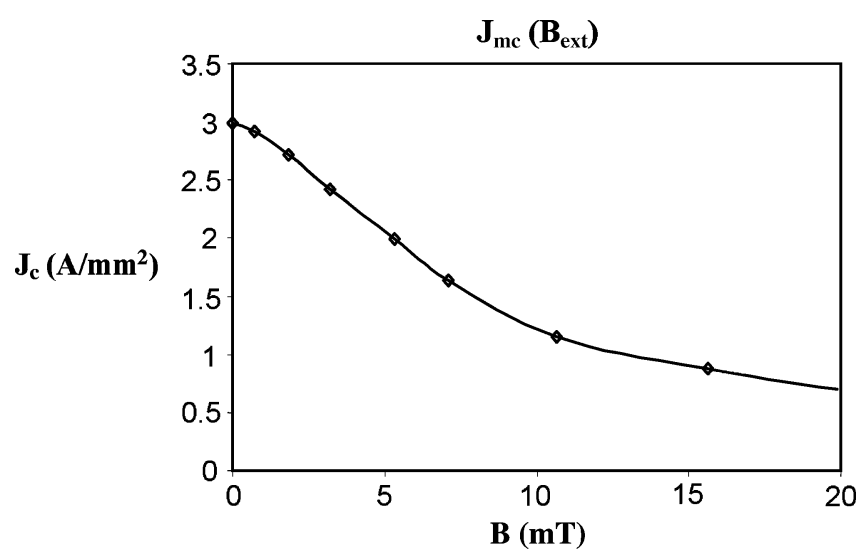

Fig. 1. Measured $J_{\mathrm{mc}}\left(B_{\text {ext }}\right)$ for a BiSCCO tube at $77 \mathrm{~K}$.

density $J_{c}$ can be deduced from the $U(I)$ measurements thanks to the following hypotheses:

1) the distribution of the current density is uniform in the superconducting material section $S$ and so $I=J . S$;

2) the electric field has only one component along the tube axis and so $U=E . L$ ( $L$ is the distance between the voltage taps).

In this case, one can deduce $E(J)$ from $U(I)$. The value of the critical current density $J_{c}=I_{c} / S$ depends on the measurement criterion. This criterion corresponds to the critical electric field $E_{c}$ that is often chosen as $1 \mu \mathrm{V} / \mathrm{cm}$. To theoretically calculate, for example, ac losses or magnetization, we can use Bean's critical state model that defines the relation between electric field $E$ and current density $J$ as $J= \pm J_{c}$ or $J=0$.

To obtain the experimental curve of $J_{c}(B)$, the tube was fed with direct current $I$ and submitted to an external magnetic flux density $B_{\text {ext }}$ parallel to the axis $[O z]$ [3]. The sample voltage drop $U$ versus $I$ is measured for different external magnetic flux densities $B_{\text {ext }}$. From the measured critical current $I_{\mathrm{mc}}\left(B_{\mathrm{ext}}\right)$ corresponding to the voltage drop equal to $1 \mu \mathrm{V} / \mathrm{cm} * \mathrm{~L}$, we can deduce $J_{\mathrm{mc}}\left(B_{\text {ext }}\right)=I_{\mathrm{mc}}\left(B_{\text {ext }}\right) / S$ supposing complete current penetration. Fig. 1 shows the curve related to this function for a BiSCCO tube at $77 \mathrm{~K}$.

$J_{\mathrm{mc}}\left(B_{\text {ext }}\right)$ and $J_{c}(B)$ are different because:

1) $J_{c}(B)$ is a microscopic quantity and $J_{\mathrm{mc}}\left(B_{\text {ext }}\right)$ is a macroscopic quantity;

2) $B$ is not equal to $B_{\text {ext }}$ because of the self magnetic flux density $B_{\mathrm{SF}}$

$$
\vec{B}=\vec{B}_{\mathrm{SF}}+\vec{B}_{\mathrm{ext}} \quad \text { and } \quad B=\sqrt{B_{\mathrm{SF}}^{2}+B_{\mathrm{ext}}^{2}} .
$$

When the value of $B_{\text {ext }}$ is sufficiently large, $B_{\mathrm{SF}}$ becomes negligible and the values of $J_{\mathrm{mc}}\left(B_{\text {ext }}\right)$ are very close to $J_{c}(B)$. When the value of $B_{\text {ext }}$ is close to $B_{\mathrm{SF}}, J_{\mathrm{mc}}\left(B_{\text {ext }}\right)$ can be very different from $J_{c}(B)$. 


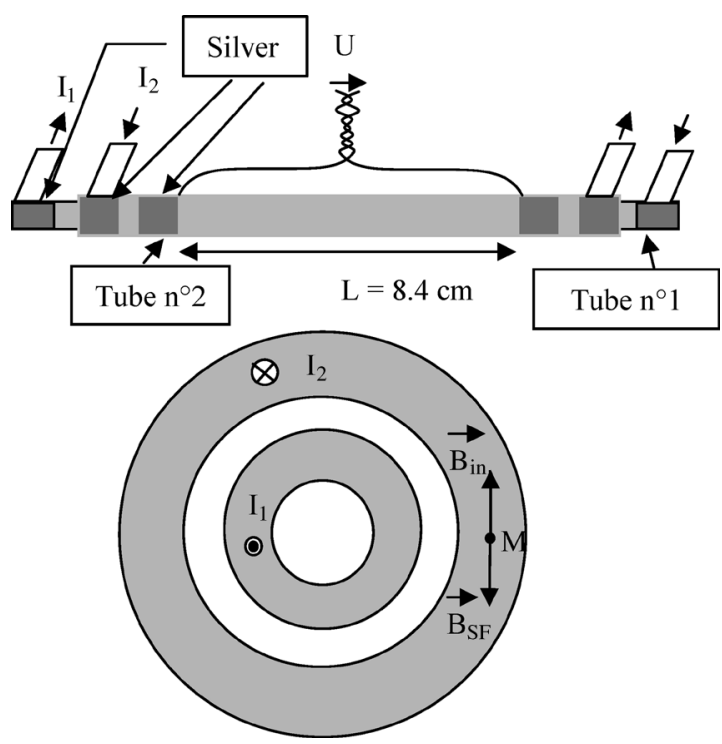

Fig. 2. Self magnetic field compensation setup and principle.

In this paper, a method of self field compensation in the electrical measurement method of $J_{\mathrm{mc}}\left(B_{\text {ext }}\right)$ for a superconducting tube is presented. This compensation allows one to make a link between $J_{\mathrm{mc}}\left(B_{\text {ext }}\right)$ and $J_{c}(B)$. The principle of compensation is valid as long as the material is isotropic.

Some authors have already studied the self field effect in superconducting tapes and its compensation [5] but not in superconducting tubes. First, the principle of our compensation method and measurements are presented. Then, a theoretical analysis is proposed.

\section{Principle of Self Magnetic Field Compensation AND MEASUREMENTS}

\section{A. Self Magnetic Field Compensation Principle}

Knowing that the self magnetic flux density in the tube is azimuthal, one has to create another azimuthal magnetic flux density $\vec{B}_{\text {in }}$ opposed to $\vec{B}_{\text {SF }}$ (Fig. 2). In this paper, we propose to generate $\vec{B}_{\text {in }}$ using another superconducting tube inside the one studied (Fig. 2). We choose a superconducting tube to minimize the losses that would be generated by a copper tube. The internal tube is noted tube no. 1 and the studied one is noted tube no. 2 (Fig. 2). The currents passing through tube no. 1 and tube no. 2 are noted, respectively, $I_{1}$ and $I_{2}$. To compensate the self field effect, $I_{1}$ and $I_{2}$ have to be opposed (Fig. 2). Without an external magnetic field, the magnetic flux density in tube no. 2 is equal to $\vec{B}_{2}=\vec{B}_{\mathrm{SF}}+\vec{B}_{\text {in }}$. So $B_{2}=0$ if $B_{\text {in }}=B_{\mathrm{SF}}$. It is a priori impossible to cancel $B_{2}$ everywhere in the tube section but one can reduce the $B_{2}$ average

$$
B_{2 \mathrm{AV}}=\frac{\varphi_{2}}{S}=\frac{2 \pi}{S} \iint_{S} \vec{B}_{2} \cdot \overrightarrow{\mathrm{ds}} .
$$

The $B_{2 \mathrm{AV}}$ reduction reduces the self field effect and increases the critical current for several magnetic fields as can be seen in the next sections. One question remains: what is the value of $I_{1}$ that minimizes the self field effect in tube no. 2 ?

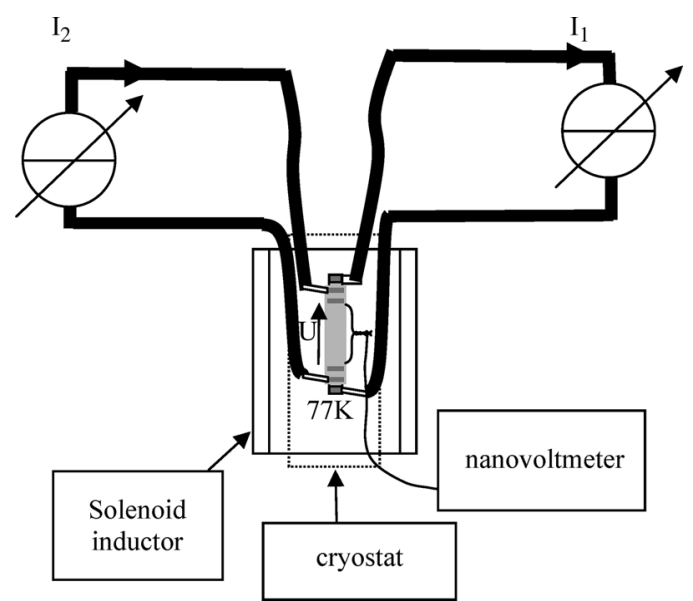

Fig. 3. Compensation experimental bench.

\section{B. Experimental Setup}

To perform the self field compensation, a special experimental setup (Fig. 3) was made.

The studied tube no. 2 consists of a hollow cylindrical current lead. It is a compacted composite of $(\mathrm{Bi}, \mathrm{Pb})_{2} \mathrm{Sr}_{2} \mathrm{Ca}_{2}\left(\mathrm{Cu}_{3} \mathrm{O}_{10+x}\right)$ with a critical temperature of $108 \mathrm{~K}$ (CAN Superconductors). The section $S$ of the superconductor is about $30 \mathrm{~mm}^{2}(+/-10 \%)$. The internal and external diameters of tube no. 2 are 8 and $10.1 \mathrm{~mm}$. The minimal critical current $I_{c 2}$ of tube no. 2, guaranteed by the manufacturer, is $80 \mathrm{~A}$ (at $77 \mathrm{~K}$ with the $1-\mu \mathrm{V}$ criterion). So the minimal critical current density $J_{c 2}$ is about $2.7 \mathrm{~A} / \mathrm{mm}^{2}$. The critical current $I_{c 1}$ of tube no. 1 is higher than $I_{c 2}$ because we want to vary $I_{2}$ between 0 and above $I_{c 2}$.

There are two independent current supplies, one for $I_{1}$ and another for $I_{2}$. A nanovoltmeter is used to measure the voltage $U$ between the two taps of tube no. 2 (the external one) (Fig. 3).

\section{Measurement Results and Discussions}

To answer to the question at the end of Section II-A, six measurements are presented:

1) $U\left(I_{2}\right)$ without external magnetic flux density $\left(B_{\text {ext }}=0\right)$ and without compensation $\left(I_{1}=0\right)$ (Fig. 4);

2) $U\left(I_{1}\right)$ for several $I_{2}$ with $B_{\text {ext }}=0$ to determine the current $I_{1}$ min that minimizes $U$ (Fig. 5);

3) $U\left(I_{2}\right)$ with $B_{\text {ext }}=0$ and with compensation $\left(I_{1}=I_{1} \min \right)$ (Fig. 4);

4) $U\left(I_{2}\right)$ with $B_{\text {ext }}>0$ and without compensation $\left(I_{1}=0\right)$ (Fig. 6);

5) $U\left(I_{1}\right)$ for several $I_{2}$ with $B_{\text {ext }}>0$ to determine the current $I_{1}$ min that minimizes $U$ (Figs. 7 and 8);

6) $U\left(I_{2}\right)$ with $B_{\text {ext }}>0$ and compensation $\left(I_{1}=\right.$ $\left.I_{1 \min }\left(B_{\text {ext }}\right)\right)$ (Fig. 9).

From the first curve $U\left(I_{2}\right)$ (Fig. 4), the critical current without external magnetic field $I_{c 20}$ of tube no. 2 is deduced: $I_{c 20}=$ 84.5 A. In a second step, several high values of $I_{2}(80,82$, 85 , and $87 \mathrm{~A})$ are chosen around $I_{c 20}$ to have sufficient voltages for measurement. Then, for each $I_{2}$ value, a $U\left(I_{1}\right)$ curve is determined (Fig. 5). One observes that the minimum of $U\left(I_{1}\right)$ is when $I_{1}$ is about $I_{2} / 2$. The determination of the exact 


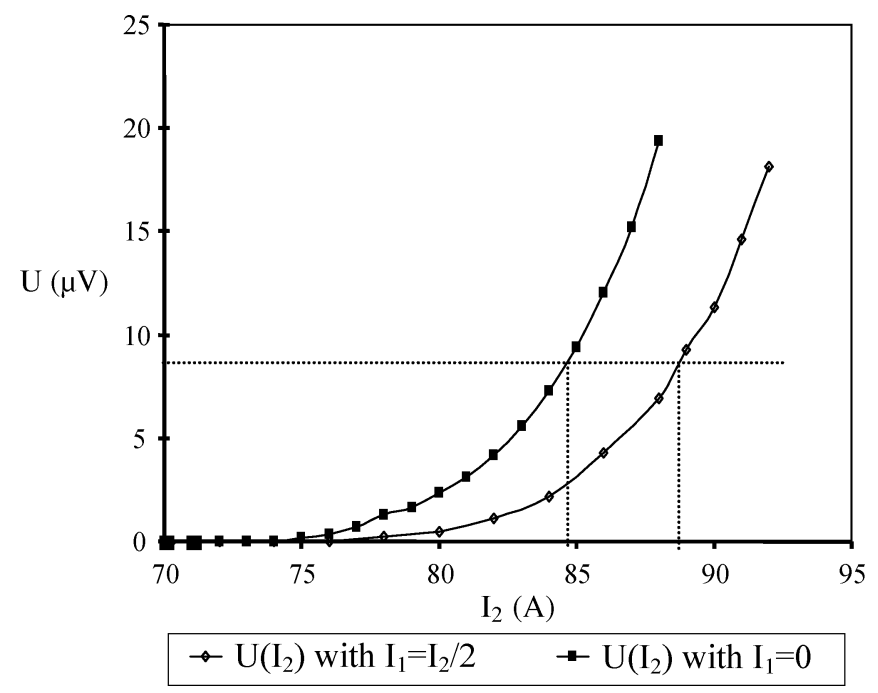

Fig. 4. Measured $U\left(I_{2}\right)$ curve of tube no. 2 with and without compensation.

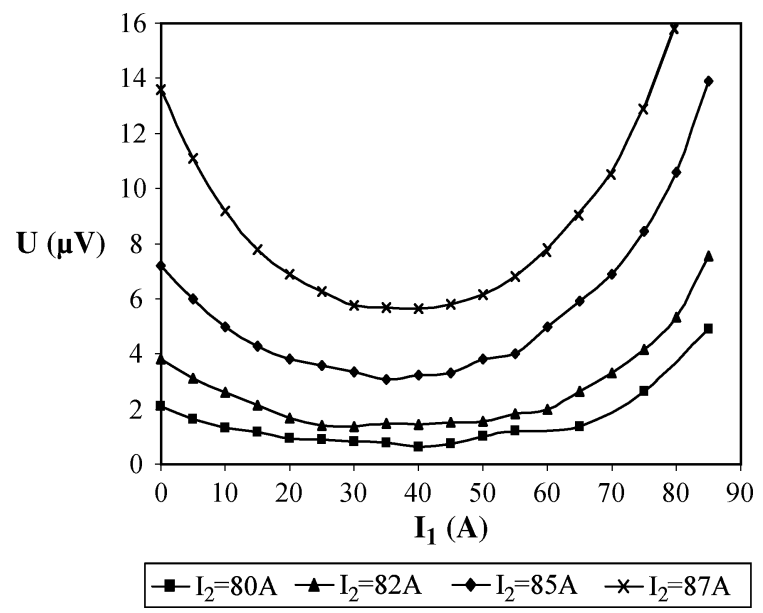

Fig. 5. Measured $U\left(I_{1}\right)$ curves for several $I_{2}$ values.

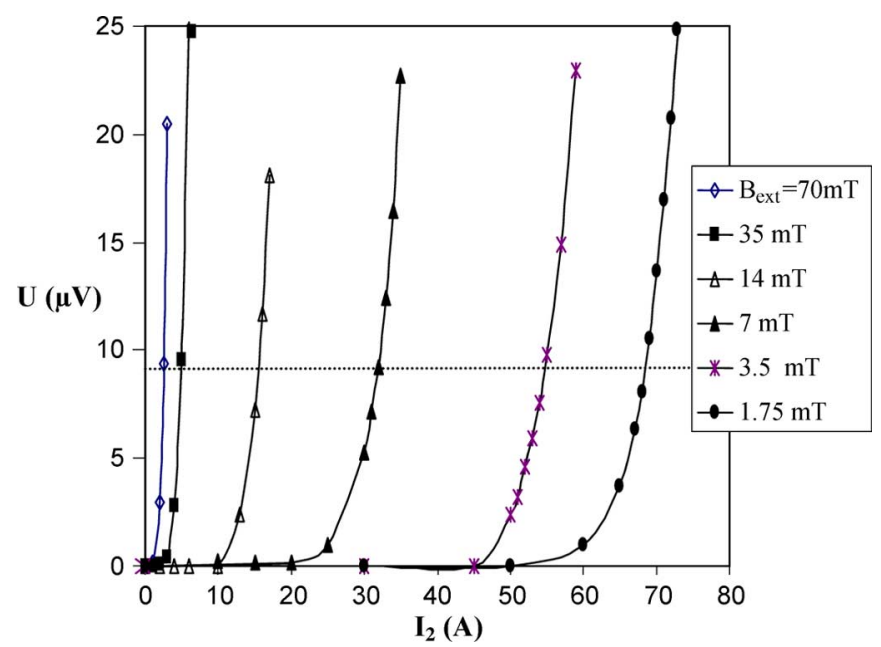

Fig. 6. Measure of sample voltage drop versus direct current for different external magnetic flux densities.

value of $I_{1} \min$ is difficult because the curve $U\left(I_{1}\right)$ is flat around $I_{1 \text { min }}$ so we decided to perform the self field compensation with $I_{1} \min =I_{2} / 2$. From the curve $U\left(I_{2}\right)$ with $I_{1}=I_{1} \min$

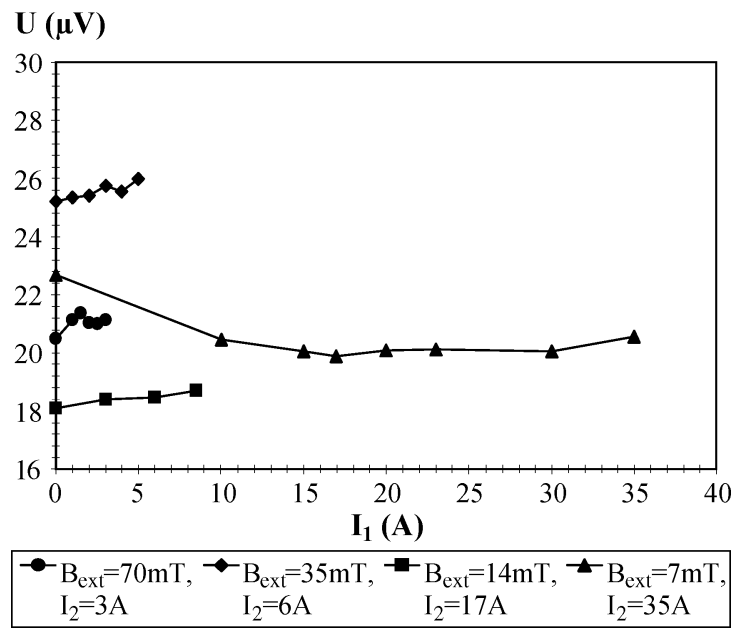

Fig. 7. Measured $U\left(I_{1}\right)$ curves for high different values of $B_{\text {ext }}$ and one value of $I_{2}$ each.

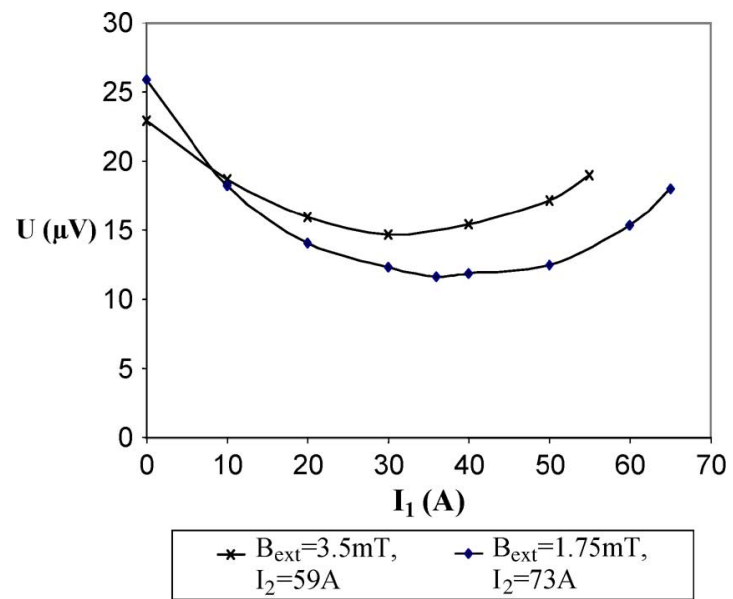

Fig. 8. Measured $U\left(I_{1}\right)$ curves for low different values of $B_{\text {ext }}$ and one value of $I_{2}$ each.

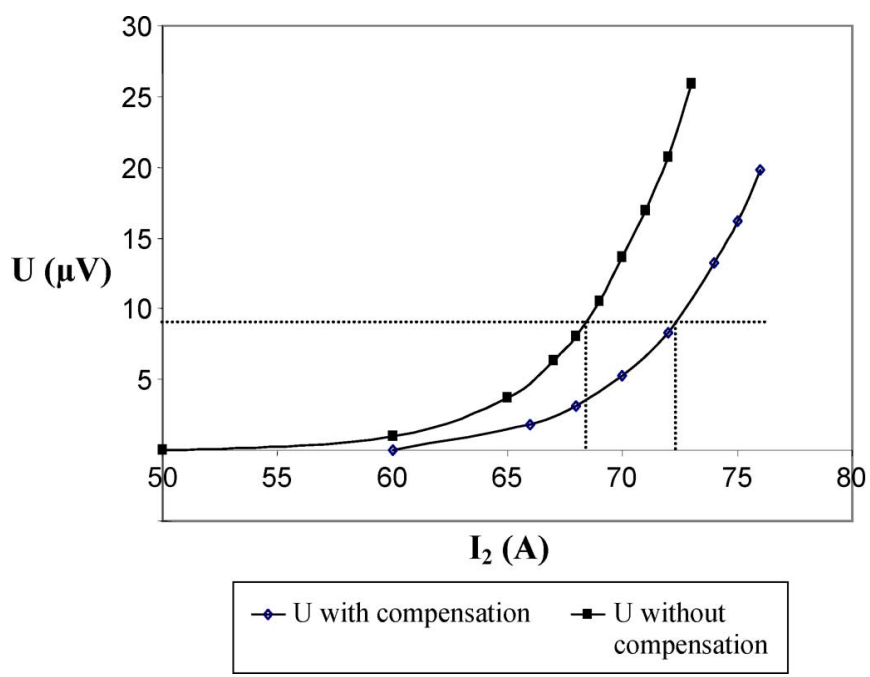

Fig. 9. Measured $U\left(I_{2}\right)$ curves of tube no. 2 with and without compensation for $B_{\text {ext }}=1.75 \mathrm{mT}$.

(Fig. 4), the compensated critical current without external magnetic field $I_{\mathrm{cc} 20}$ of tube no. 2 is deduced: $I_{\mathrm{cc} 20}=88.5 \mathrm{~A}$. 


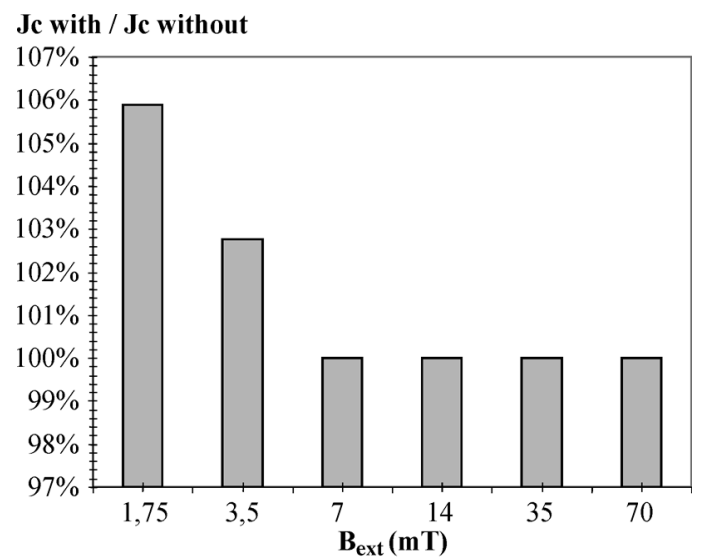

Jc with compensation / Jc without compensation

Fig. 10. Measured $J_{\mathrm{mc}}$ with and without self field compensation versus $B_{\text {ext }}$.

Thanks to this partial self field effect compensation, the critical current was increased by almost $5 \%$. In a fourth step, the sample voltage drop $U\left(I_{2}\right)$ is measured without compensation $\left(I_{1}=0\right)$ for different external magnetic flux densities $B_{\text {ext }}$ (Fig. 6) from a higher value than self field $(70 \mathrm{mT})$ to a lower value $(1.75 \mathrm{mT}$; the maximal self magnetic flux density of tube no. 2 is about $4 \mathrm{mT}$ for $\left.I_{2}=100 \mathrm{~A}\right)$. The curve $J_{\mathrm{mc}}\left(B_{\text {ext }}\right)$ without compensation is deduced (Fig. 1). For each value of $B_{\text {ext }}$, we choose only one value of $I_{2}$ for one $U\left(I_{1}\right)$ curve to have significant voltage $(15 \mu \mathrm{V}<U<25 \mu \mathrm{V})$. There are two kinds of $U\left(I_{1}\right)$ curves. If $B_{\text {ext }}$ is significantly higher than the self magnetic flux density ( 7 to $70 \mathrm{mT}$, Fig. 7), the curve is flat and the compensation is not valid. For example, for $B_{\text {ext }}=7 \mathrm{mT}$ and $I_{2}=35 \mathrm{~A}$, the self magnetic flux density is about $1.4 \mathrm{mT}$ and $B=\sqrt{7^{2}+1.4^{2}}=7.1 \approx B_{\text {ext }}$. If $B_{\text {ext }}$ is close to the self magnetic flux density ( 3.5 and $1.75 \mathrm{mT}$, Fig. 8), one still observes that the minimum of $U\left(I_{1}\right)$ appears when $I_{1}$ is about $I_{2} / 2$. For example, for $B_{\text {ext }}=3.5 \mathrm{mT}$ and $I_{2}=59 \mathrm{~A}$, the self magnetic flux density is about $2.4 \mathrm{mT}$ and $B=\sqrt{3.5^{2}+2.4^{2}}=4.3 \gg B_{\text {ext }}$. In the sixth step, the curve $U\left(I_{2}\right)$ (Fig. 9) with $I_{1} \mathrm{~min}$ and for $B_{\text {ext }}=1.75 \mathrm{mT}$ is presented. The compensated critical current $I_{\mathrm{cc} 2}$ with the external magnetic field of tube no. 2 is deduced: $I_{\mathrm{cc} 2}\left(B_{\text {ext }}=1.75 \mathrm{mT}\right)=72 \mathrm{~A}$. For $B_{\text {ext }}=3.5 \mathrm{mT}, I_{\mathrm{cc} 2}\left(B_{\text {ext }}=3.5 \mathrm{mT}\right)=56 \mathrm{~A}$. Finally, $J_{\mathrm{mc}}\left(B_{\text {ext }}\right)$ curves with and without compensation are plotted (Fig. 10). In the low field regime, the superposition of external magnetic field with the self magnetic field has an influence on $J_{\mathrm{mc}}$, and the compensation permit to increase $J_{\mathrm{mc}}$. Improvements made to $J_{\mathrm{mc}}$ are weak but this experiment validates the compensation principle. In the high magnetic field regime, the self magnetic field has no influence on $J_{\mathrm{mc}}$, and one can say that $J_{c}(B)=J_{\mathrm{mc}}\left(B_{\mathrm{ext}}\right)$.

\section{THEORETICAL ANALYSIS}

In this section, a theoretical analysis of the self field compensation is presented. We want to find the value of $I_{1}$ min that maximizes the critical current $I_{c 2}$ and so the critical current density $J_{c 2}$ for $B_{\text {ext }}=0$. We choose $B_{\text {ext }}=0$ because it is the best compensation case and it is the simplest calculation case. Indeed in this case, the current density is along the tube axis. On

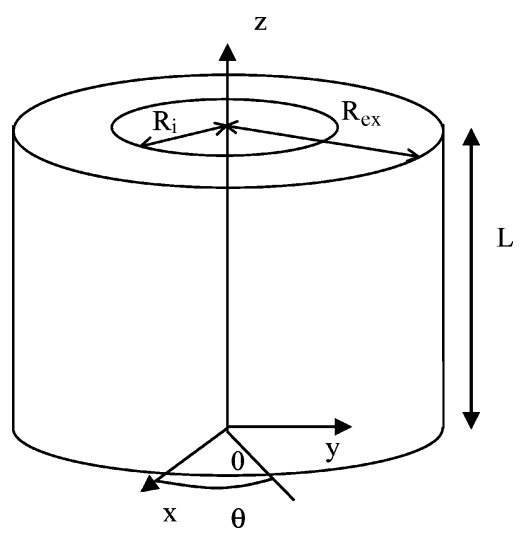

Fig. 11. Reference frame and dimensions of the superconducting tube.

the other hand, if $B_{\text {ext }} \neq 0$, the current density adopts a helical path around the tube.

The case of a superconducting tube fed by a dc current $I_{2}$ and exposed to an internal magnetic flux density $B_{\text {in }}$ is studied. The dimensions of the tube (Fig. 11) are internal radius $R_{\text {in }}$, external radius $R_{\mathrm{ex}}$, section $S$, and length $L$. The $z$-axis is along the axis of the tube. The relation between the magnetic flux density and the current density is governed by the Maxwell equation

$$
\overrightarrow{\operatorname{rot}} \vec{B}=\mu_{0} . \vec{J}
$$

By symmetry, the current density is oriented along the $[O z]$ axis. In addition $B_{\mathrm{in}}(r), B_{\mathrm{SF}}(r)$, and the current density in tube no. $2 J_{2}(r)$ have only one component

$\vec{B}_{\mathrm{SF}}(r)=B_{\mathrm{SF}}(r) \cdot \vec{u}_{\theta}, \overrightarrow{B_{\mathrm{in}}}(r)=-B_{\mathrm{in}}(r) \cdot \vec{u}_{\theta}, \vec{J}_{2}(r)=J_{2}(r) \cdot \vec{u}_{z}$

The magnetic flux density in the superconducting material is the sum of the different magnetic flux densities

$$
\vec{B}(r, t)=\left(B_{\mathrm{SF}}(r)-B_{\mathrm{in}}\right) \cdot \vec{u}_{\theta} .
$$

The analytical calculation of the magnetic flux density and current density distributions in the superconducting material is difficult [3] because (1) with $J_{2}(r)=J_{c 2}(B)$ has to be solved. One can simplify calculation of these distributions with three hypotheses.

1) To calculate $B_{\mathrm{SF}}(r), J_{c 2}$ is taken as a constant (Bean's model) and so

$$
\frac{\mathrm{dB}_{\mathrm{SF}}(r)}{\mathrm{dr}}=J_{c 2} .
$$

2) To calculate $J_{2}(r, t)=J_{c 2}(B)$, a linear relation is chosen $J_{c 2}(B)=J_{c 0}\left(1-\left(|B(r, t)| / B_{j 0}\right)\right) . J_{c 0}$ and $B_{j 0}$ are constants and depend on the superconducting material.

3) The critical current $I_{c 2}=\int_{S} J_{c 2} . d s$ and the full penetration current $I_{p 2}$ [3] are equal.

With these hypotheses one can calculate $I_{c 2}$ as follows:

$$
\begin{aligned}
I_{c 2} & =\iint_{S} \vec{J} . d \vec{s}=\iint_{S} J_{c} d s=\iint_{S} J_{c 0}\left(1-\frac{|B(r, t)|}{B_{j 0}}\right) d s \\
& =J_{c 0} \cdot S-\frac{J_{c 0}}{B_{j 0}}\left|\iint_{S} B(r, t) d s\right|=J_{c 0} . S-\frac{J_{c 0} S}{B_{j 0}}\left|B_{\mathrm{AV}}\right|
\end{aligned}
$$




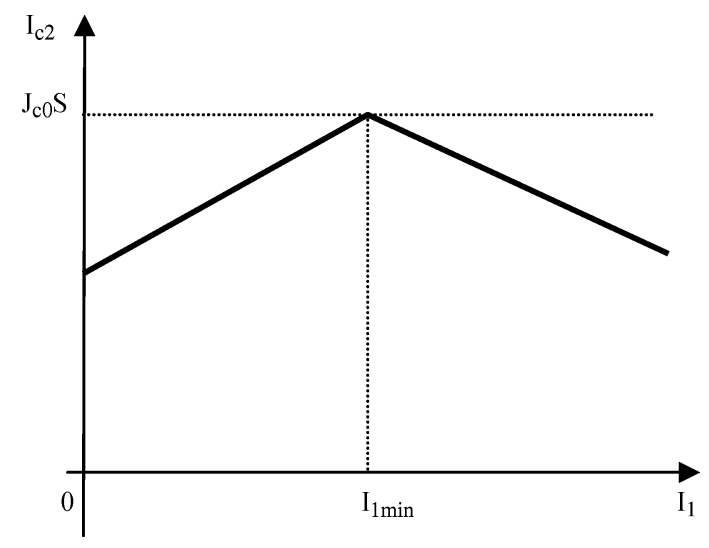

Fig. 12. Critical current $I_{c 2}$ of the studied superconducting tube versus $I_{1}$.

with $B_{\mathrm{AV}}=\left(\varphi_{2} / S\right)=(2 \pi / S) \int_{R_{\mathrm{in}}}^{R_{\mathrm{ex}}} B(r) . r . d r$ and $B(r)=$ $B_{\mathrm{SF}}(r)-B_{\text {in }}(r)$.

So maximizing $I_{c 2}$ is equivalent to minimizing $\left|B_{\mathrm{AV}}\right|$.

Equation (2) and $B_{\mathrm{SF}}\left(R_{\mathrm{in}}\right)=0$ allows one to calculate $B_{\mathrm{SF}}(r)$

$$
B_{\mathrm{SF}}(r)=\mu_{0} . J_{c 2} \cdot\left(r-R_{\mathrm{in}}\right) .
$$

The internal tube that creates $B_{\text {in }}$ is viewed as an infinite long wire and so

$$
\begin{aligned}
B_{\mathrm{in}}(r)= & \frac{\mu_{0} I_{1}}{2 \pi r} \\
B_{\mathrm{AV}}= & \frac{2 \pi}{S} \int_{R_{\mathrm{in}}}^{R_{\mathrm{ex}}}\left[\mu_{0} J_{c 2}\left(r-R_{\mathrm{in}}\right)-\frac{\mu_{0} I_{1}}{2 \pi r}\right] \cdot r . \mathrm{dr} \\
= & \frac{2 \pi}{S}\left[\mu_{0} J_{c 2}\left(\frac{R_{\mathrm{ex}}^{3}}{3}+\frac{R_{\mathrm{in}}^{3}}{6}-\frac{R_{\mathrm{in}} R_{\mathrm{ex}}^{2}}{2}\right)\right. \\
& \left.\quad-\frac{\mu_{0} I_{1}}{2 \pi}\left(R_{\mathrm{ex}}-R_{\mathrm{in}}\right)\right] .
\end{aligned}
$$

The relation $I_{c 2}\left(I_{1}\right)$ is represented in Fig. 12 and we can easily obtain $I_{1}$ min from $B_{\mathrm{AV}}=0$

$$
I_{1 \min }=\frac{2 \pi J_{c 2}}{R_{\mathrm{ex}}-R_{\mathrm{in}}}\left(\frac{R_{\mathrm{ex}}^{3}}{3}+\frac{R_{\mathrm{in}}^{3}}{6}-\frac{R_{\mathrm{in}} R_{\mathrm{ex}}^{2}}{2}\right) .
$$

We can apply this formula to our superconducting tube. The critical current without external magnetic field is $I_{c 2}=84.5 \mathrm{~A}$ and $J_{c 2}=84.5 / 30.10^{-6}=2.8 .10^{6} \mathrm{~A} / \mathrm{mm}^{2}$. One thus finds $I_{1 \min }=45.2 \mathrm{~A}$. This value is close to $I_{c 2} / 2$ as it was shown in the experimental part. Despite the strong hypothesizes, the $I_{1 \text { min }}$ calculation validates the experimental results.

\section{CONCLUSION}

This paper presented the self field effect compensation in a superconducting tube for the measurements of the $J_{c}(B)$ curve. A special experimental arrangement allows results in an increase in the measured critical current when the external magnetic field is close to the self field. It consists of placing another superconducting tube inside the studied one. This second tube creates a magnetic field opposed to the self field to reduce the self field effect. Several presented experiments show that the compensation is real and allow determining the $J_{c}(B)$ curve with compensation. This curve is slightly higher than the curve without compensation. A theoretical analysis based on the Bean model and some strong hypotheses are presented. For compensating the self field effects, experimental and theoretical results show that the internal tube current must be equal to one half of the studied tube current. The proposed compensation is not perfect, but the experiments and the theoretical analysis allow validating the compensation principle. Finally, this work opens the door to a further work: what new arrangement would allow for a better compensation of the self field inside the superconducting tube? This is an inverse problem that consists of finding the external magnetic field configuration which creates an azimuthal magnetic field perfectly opposed to the self field of the studied tube.

\section{REFERENCES}

[1] F. Gomory and L. Gherardi, "Transport AC losses in round superconducting wire consisting of two concentric shells with different critical current density," Physica C, vol. 280, pp. 151-157, 1997.

[2] M. Daumling, "AC loss in two ac carrying superconducting concentric tubes-The duo block model," Physica C, vol. 403, pp. 57-59, 2004.

[3] B. Douine, K. Berger, J. Leveque, D. Netter, and A. Rezzoug, "Influence of $\mathrm{Jc}(\mathrm{B})$ on the full penetration current of superconducting tube," Physica C, vol. 443, pp. 23-28, 2006.

[4] P. Vanderbemden, "Determination of Critical Current in Bulk High Temperature Superconductors by Magnetic Flux Profile Measuring Methods," Ph. D. Thesis, Univ. of Liège, Liège, Belgium, 1999.

[5] S. Spreafico, L. Gherardi, S. Fleshler, D. Tatelbaum, J. Leone, D. Yu, and G. Snitchler, "The effect of self field on current capacity in Bi-2223 composite strands," IEEE Trans. Appl. Supercond., vol. 9, no. 2, pp. 2159-2162, Jun. 1999.

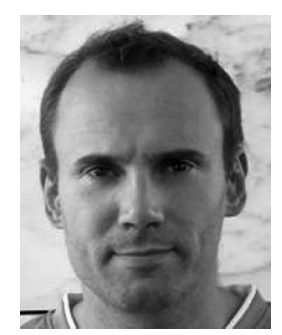

Bruno Douine was born in Montereau, France, in 1966. He received the $\mathrm{Ph}$. D. degree in electrical engineering from the University of Nancy, France, in 2001.

$\mathrm{He}$ is currently a Lecturer at the University of Nancy. As a member of the Groupe de Recherche en Electrotechnique et Electronique de Nancy, his main subjects of research concern characterization and modelization of superconducting material.

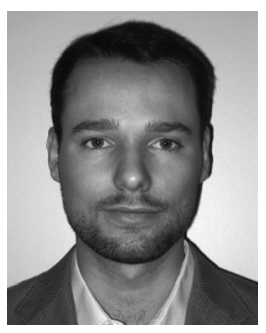

Kévin Berger was born in Montbéliard, France, on January, 16, 1980. He received the Ph.D. degree in electrical engineering from Université Henri Poincaré, Nancy, France, in 2006.

$\mathrm{He}$ then joined the Grenoble Electrical Engineering Laboratory (G2Elab) and the Néel Institut, Grenoble in 2006 as a post-doctoral researcher in order to work on superconductor modeling using FLUX software and a conduction cooled SMES. His research interests deal with the design and modeling of superconducting devices like cryomagnets while taking into account coupled magneto-thermal behavior. His research topics also include electrical characterization of superconducting material and $\mathrm{AC}$ loss measurements. 


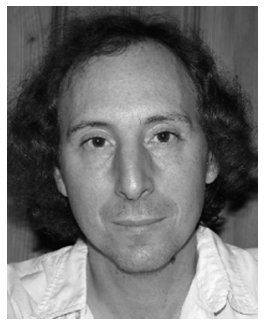

Jean Lévêque was born in Angers, France, in 1963. $\mathrm{He}$ received the $\mathrm{Ph}$. D. degree in electrical engineering from the University of Grenoble, France, in 1993.

$\mathrm{He}$ is currently Professor at the University of Nancy, France. As a member of the Groupe de Recherche en Electrotechnique et Electronique de Nancy, his main subjects of research concern characterization and modelization of superconducting material and applications.

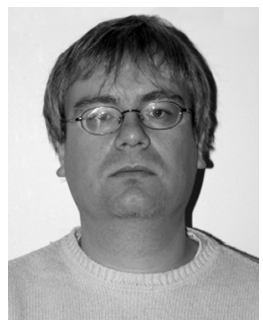

Denis Netter was born in Auchel, France, in 1969. $\mathrm{He}$ received the $\mathrm{Ph}$. D. degree in electrical engineering from the University of Nancy, France, in 1997.

$\mathrm{He}$ is currently a Lecturer at the University of Nancy. As a member of the Groupe de Recherche en Electrotechnique et Electronique de Nancy, his main subjects of research concern superconducting applications and stochastic methods to calculate nonlinear diffusion of the magnetic field in superconducting material.

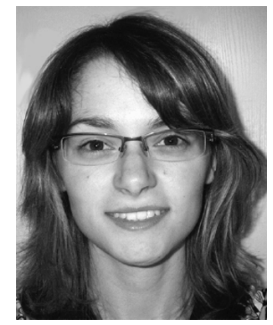

Olivia Arbey was born in France, in 1984. She received the M.S. and Engineering degrees from ENSEM Institut National Polytechnique de Lorraine (INPL) in 2007. She is currently working toward the Ph. D. degree at FEMTO Institute at Besançon, France.

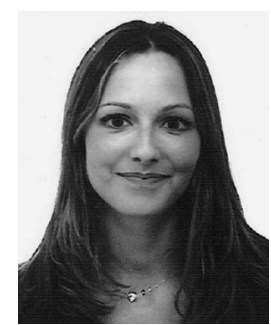

Nancy Barthelet was born in France, in 1982. She received the M.S. and Engineering degrees from ENSEM Institut National Polytechnique de Lorraine (INPL) in 2007. 